\title{
Biochemical Characteristics of an Alanine Racemase from Xanthomonas oryzae pv. oryzae
}

\author{
Han-Chul Kang*, Sang-Hong Yoon, Chang-Muk Lee, and Bon-Sung Koo \\ Department of Functional Bio-material, National Academy of Agricultural Science, \\ Rural Development Administration, Suwon, 441-707, Republic of Korea
}

Received July 27, 2011; Accepted October 14, 2011

\begin{abstract}
A gene encoding a putative alanine racemase in Xanthomonas. oryzae pv. oryzae was cloned, expressed and characterized. Expression of the cloned gene was performed in Escherichia coli BL21(DE3)pLys using a pET-21(a) vector harbouring $6 \times$ histidine tag. Purification of the recombinant alanine racemase by affinity chromatography resulted in major one band by sodium dodecyl sulfate polyacryl amide gel electrophoresis analysis, showing about $45 \mathrm{kDa}$ of molecular weight. The alanine racemase gene, cloned in this experiment, appears to be constitutively expressed in $X$. oryzae, as analyzed by reverse transcriptase polymerase chain reaction. The enzyme was the most active toward L-alanine and secondly D-alanine, showing a racemic reaction, thus the enzyme is considered as an alanine racemase. The enzyme was considerably activated by addition of pyridoxal-5-phosphate (PLP), showing that $75 \%$ increase in activity was observed at $0.3 \mathrm{mM}$, compared with control. D-Cysteine as well as L-cysteine significantly inhibited the enzyme activity. The inhibitions by cysteines were more prominent in the absence of PLP, showing 9 and $5 \%$ of control activity at $2 \mathrm{mM}$ of addition, respectively. The enzyme was the most active at $\mathrm{pH} 8.0$ and more stable at alkaline $\mathrm{pHs}$ than acidic $\mathrm{pH}$ condition.
\end{abstract}

Key words: alanine racemase, characteristics, Xanthomonas oryzae

Alanine racemase (EC 5.1.1.1) catalyzes the interconversion of L-alanine and D-alanine and is one of the pyridoxal-5phosphate (PLP) dependent enzymes. Although L-amino acids are predominant in living organisms, D-amino acids including Dalanine are also distributed ubiquitously in microbes. D-Alanine is required for the biosynthesis of peptidoglycan layer which is necessary for the cell membrane of prokaryotes. Thus the alanine racemase is considered as one of essential enzymes in prokaryotes. Almost all bacteria contain alanine racemases, but the enzyme is generally absent in higher eukaryotes with only some exceptions. In eukaryotes, alanine racemase is involved in D-alanine metabolism in yeast, Schizosaccharomyces pombe [Uo et al., 2001a; 2001b], osmotic regulation in a freshwater crayfish, Procambarus clarkia [Shibata et al., 2000] or brackishwater mollusk, Corbicula japonica [Nomura et al., 2001]. Biochemical characterization of the enzyme has shown that eukaryotic alanine racemases are distinct from those of microbial enzymes in quaternary structure, $\mathrm{pH}$-dependency, PLP requirement, and kinetic properties. Alanine racemase is encodes by alr gene which is constitutively expressed in the microbes

*Corresponding author

Phone: +82-31-299-1694; Fax: +82-31-299-1672

E-mail: hckang09@korea.kr

http://dx.doi.org/10.3839/jabc.2011.038
[Strych et al., 2000; Saito et al., 2007; Zhang et al., 2007]. Another gene of alanine racemase, $d a d x$, is induced by the presence of high concentration of L-alanine and also involved in the interconversion of alanine [Lobocka et al., 1994; Zhang et al., 2007].

By reason of unique presence in bacteria and of its biochemical role, alanine racemase has often been proposed as an attractive target protein for the development of new antimicrobial agents [Badet and Walsh, 1985; Silverman, 1988]. Some substances which inhibit the biosynthesis of peptidoglycan have been known and these materials include D-cysteine, Dcycloserine (4-amino-3-isoxazolidinone) and D-carbamyl-Dserine. The target of inhibition was known to be alanine racemase [Preston and Douchit, 1984; Hoffmann et al., 1994; Noda et al., 2004]. D-Cycloserine is general inhibitor for PLPdependent enzymes including alanine racemase. Alanine analogues including $\beta, \beta, \beta$,trifluoroalanine [Faraci and Walsh, 1989], alanine phosphonate [Copie et al., 1988], 1-amino-cyclo propane phosphonate [Erion and Walsh, 1987], and $\beta$-chloro and $\beta$-fluoalanine [Wang and Walsh, 1978] were known to inhibit the activity of alanine racemase. Contrary to the finding that Dcysteine inhibits an alanine racemase, another finding showed that an alanine racemase from $E$. coli was not inhibited by Dcysteine [Lambert and Neuhaus, 1972]. Enzyme activity of an alanine racemase from Lactobacillus was enhanced by a 
sulfhydryl compound, glutathione [Johnston, 1969]. Enzyme activity of an alanine racemase from Tolypocladium niveum was reported to be increased by thiol reducing agents such as glutathione, mercaptoethanol or dithiothreitol [Hoffmann et al., 1994]. In the case of alanine racemase from Lactobacillus fermenti, the enzyme activity was increased by addition of $\beta$ mercaptoethanol or glutathione but the activity decreased by dithiothreitol [Johnston, 1969]. Such controversial results necessitate further research of alanine racemase, especially in the part of active site and catalytic mechanism.

Alanine racemase is also valuable in the development of a process for the production of D-amino acid, which is widely used in the field of agro-chemical or drug materials [Kuniki et al., 2007]. In this regard, a gene encoding a putative alanine racemase was isolated from $X$. oryzae based on the data in NCBI gene bank and expressed in E. coli. This paper describes the expression of a putative alanine racemase gene of $X$. oryzae and confirmation and characterization of the alanine racemase.

\section{Materials and Methods}

Bacterial strains and culture media. $X$ oryzae pv. oryzae (ATCC 35393) was obtained from Korean Agricultural Culture Collection. The cells were cultured using Luria broth medium (LB) supplemented with sucrose $(5 \mathrm{~g} / \mathrm{L})$, yeast extract $(10 \mathrm{~g} / \mathrm{L})$, and peptone $(5 \mathrm{~g} / \mathrm{L})$ [Sambrook and Russel, 2001]. E. coli DH5 $\alpha$ was used as a cloning host for the gene encoding a putative alanine racemase of $X$. oryzae. E. coli BL21(DE3)pLys, comprising the gene for T7 RNA polymerase under the control of lac promoter, was used for the expression of an alanine racemase gene. These $E$. coli strains were stock-cultured and generally grown using LB medium which was supplemented with appropriate concentration of antibiotics.

Gene cloning. For the purpose of isolating an alanine racemase gene, $X$. oryzae cells were cultured using the medium for $24 \mathrm{~h}$. General DNA manipulations including preparation of total genomic DNA were performed according to routine methods [Sambrook and Russel, 2001]. A putative alanine racemase gene (NCBI accession number, NC 006834; GI, 58579623) was amplified by PCR technique using a sense primer, 5'-atgcgt cetgcgcaagcgtcgatc-3' and an antisense primer, 5'-ccgcgctgcaac ctcgeccactgc-3. Secondary PCR was intended to attach NdeI adaptor site using the first PCR product as a template DNA. The primer of this PCR was as follows: a sense primer, 5'-catatg tgtcctaggtcatggtggttt-3' (underlined catatg is for NdeI adaptor site) and the same antisense primer as that for the first PCR. The amplified gene was designed to elimninate a stop codon for the subsequent preparation of His6-tagged recombinant protein. The PCR product (ca. $1.1 \mathrm{~kb}$ ) was isolated and ligated into a pGEM$\mathrm{T}$ Easy vector (Promega, Sanfrancisco, CA). The ligation mixture was transformed into $E$. coli $\mathrm{DH} 5 \alpha$ cells by a heatshock method, then inoculated in the LB agar medium supplemented with ampicillin $(100 \mu \mathrm{g} / \mathrm{mL})$, isopropyl $\beta$-D-thiogalacto pyranoside (IPTG; $0.5 \mathrm{mM}$ ), and 5-bromo-4-chloro-3indolyl $\beta$-D-galacto-pyranoside $(75 \mu \mathrm{g} / \mathrm{mL})$. After culture at $37^{\circ} \mathrm{C}$ for $24 \mathrm{~h}$, desired colonies were further cultured in to a 5 $\mathrm{mL}$ LB medium containing ampicillin, followed by a plasmid isolation. The evident insertion of a desired gene was confirmed by both PCR technique and DNA sequence analysis. DNA was dideoxy-cycle-sequenced with fluorescent terminators (Big Dye, Applied Biosystems, Foster City, CA) in an Applied Biosystems ABI Prism 377 automated DNA sequencer.

Plasmid construction. The pGEM-T Easy vector inserted with the putative alanine racemase gene was double digested by NdeI and SalI restriction enzymes. The digested gene was inserted into a pET-21(a) vector which was also digested by the same enzymes. The constructed pET-21(a) vector harboring the gene was named pET-21-ala and transformed into E. coli DH5 $\alpha$ cells. After incubation of the cells in LB-agar medium containing ampicillin $(100 \mu \mathrm{g} / \mathrm{mL})$ for $18 \mathrm{~h}$, the desired colony harbouring the pET-21-ala was further cultured in $5 \mathrm{~mL} \mathrm{LB}$ liquid medium containing ampicillin, followed by isolation of pET-21-ala. Insertion of the gene into the pET-21(a) was confirmed by both double digestion with NdeI and SalI and DNA sequence method as described.

Expression and preparation of cell-free extract. The pET21-ala was transformed into E. coli BL21(DE3)pLys cells in order to express the gene inserted. The transformed cells were inoculated in LB-agar medium containing ampicillin $(100 \mu \mathrm{g} /$ $\mathrm{mL}$ ). After culture for $18 \mathrm{~h}$, the desired colony harboring the pET-21-ala was further cultured in $5 \mathrm{~mL}$ LB medium supplemented with ampicillin. The incubation was continued with shaking at $37^{\circ} \mathrm{C}$ until the $\mathrm{A}_{600 \mathrm{~nm}}$ reached 0.4 , and the cells were inoculated in to $200 \mathrm{~mL}$ of the same medium to obtain sufficient quantity of alanine racemase. After further incubation for $4 \mathrm{~h}$, the induction was performed by adding IPTG to a final concentration of 1.0 $\mathrm{mM}$. An additional culture was carried out for $8 \mathrm{~h}$ with slow shaking $(50 \mathrm{rpm})$ at $25^{\circ} \mathrm{C}$. The cells were harvested by centrifugation and washed with buffer A (20 mM Tris- $\mathrm{HCl}, \mathrm{pH}$ $7.5,50 \mathrm{mM} \mathrm{NaCl}$, and $5 \%$ glycerol). The cells suspended in buffer A were disrupted by sonication on ice, followed by centrifugtion at $10,000 \mathrm{~g}$ for $5 \mathrm{~min}$ for clarification.

Affinity purification of the His6-tagged alanine racemase. The cell-free extract suspended in $50 \mathrm{~mL}$ of the buffer A was loaded directly into a His-Bind Resin column $(1 \mathrm{~cm} \times 5 \mathrm{~cm})$ previously charged with $\mathrm{Ni}$ (II) ion and equilibrated with the same buffer. The column was washed with the same buffer, then protein was eluted with an elution buffer $(50 \mathrm{mM}$ Tris- $\mathrm{HCl} \mathrm{pH}$ $7.5,5 \%$ glycerol, and a linear gradient of $0-500 \mathrm{mM}$ imidazole) at a flow rate of $0.5 \mathrm{~mL} / \mathrm{min}$. The fraction containing an alanine 
racemase was traced by assaying the enzyme activity with each fraction. The fractions pooled with alanine racemase were then collected and dialyzed with buffer $\mathrm{A}$ in order to eliminate excessive imidazole. The active fraction was used for analysis of sodium dodecyl sulfate polyacryl amide gel electrophoresis (SDS-PAGE) and characterization study of the enzyme.

Assay of alanine racemase. The alanine racemase activity was measured by the colorimetric method of Shibata et al. [2000] with minor modifications. In brief, the reaction of converting L-alanine to D-alanine was performed in a $0.5 \mathrm{~mL}$ mixture containing $10 \mathrm{mM}$ L-alanine, $100 \mathrm{mM}$ Tris- $\mathrm{HCl}$ (pH 8.0), $0.2 \mathrm{mM} \mathrm{NADH}, 0.2 \mathrm{U}$ of D-amino acid oxidase (from porcine kidney, Sigma, St. Louis, MO), and 2.5 U of L-lactate dehydrogenase (from Lactobacillus leichmanii, Sigma). The reaction was started by addition of $50 \mu \mathrm{L}$ enzyme preparation. After incubation at $37^{\circ} \mathrm{C}$ for $30 \mathrm{~min}$, the enzyme activity was tested spectrophotometrically by measuring decrease in absorbance $340 \mathrm{~nm}$. For the assay of reaction converting D-alanine to Lalanine, reaction mixture was consisted of $0.2 \mathrm{U}$ L-alanine dehydrogenase (from Bacillus subtilis, Sigma,), $20 \mathrm{mM}$ Dalanine, and $2.5 \mathrm{mM} \mathrm{NAD}{ }^{+}$. The enzyme activity of this direction was tested by measuring increase in absorbance 340 $\mathrm{nm}$. One unit of enzyme activity was defined as the amount of $\mathrm{L}$ or D-alanine $(\mu \mathrm{mol})$ produced per min per $\mathrm{mg}$ protein.

Test of substrate specificity Substrate specificity of the racemase was based upon measuring the amount of L- or Damino acid produced by the enzymatic reaction. Racemase activity converting L-amino acid to D-amino acid was measured using different $\mathrm{L}$-amino acids as substrate. In this case, D-amino acids produced by the enzyme was measured by the same method of alanine racemase assay, since detection of D-amino acid is based upon the use of D-amino acid oxidase by the same way. Detection of L-amino acid produced by the enzymatic reaction was performed using L-amino acid oxidase (from Crotalus adamanteus, Sigma) in place of D-amino acid oxidase. In general, L- or D-amino acids can be racemized, each other, by heat treatment [Liardon and Hurrel, 1983] as well as by the reaction of racemase. Therefore all amino acids used in this experiment were filter-sterilized in place of heat-mediated sterilization and freshly prepared just before use.

Inhibition of alanine racemase by amino acids. The alanine racemase activity was measured for the reaction converting Lalanine to D-alanine and vice verse in the presence of $\mathrm{L}$ - or Damino acids as potential inhibitor. The enzymatic reaction and measurement of activity were performed as described above under standard assay condition. Inhibition of alanine racemase activity was assessed by measuring the residual activity of alanine racemase.

Effect of pH on the activity and stability. The effect of different $\mathrm{pH}$ on the enzyme activity was determined under the standard assay method, with exception of buffer system. The enzymatic reactions at $\mathrm{pH} 4.0-5.5,5.5-7.0$, and 7.0-9.0 were performed with $50 \mathrm{mM}$ citrate phosphate, potassium phosphate, and Tris- $\mathrm{HCl}$ buffer, respectively. For the test of $\mathrm{pH}$ stability, the enzyme fraction $(50 \mu \mathrm{L})$ was distributed into different buffers $(200 \mu \mathrm{L})$ showing different $\mathrm{pH}$ values ranging from 3.0 to 10.0 : citrate phosphate ( $\mathrm{pH} 3.0$ to 5.0), potassium phosphate ( $\mathrm{pH} 6.0$ to 7.0), and Tris- $\mathrm{HCl}$ buffer ( $\mathrm{pH} 8.0$ to 10.0). After keeping for 4 $\mathrm{h}$ at room temperature (about $25^{\circ} \mathrm{C}$ ), the aliquots were removed, and the alanine racemase activity was measured under the standard assay condition.

Other analytical methods. Total RNA was extracted from $X$. oryzae using a commercial kit (Promega). An expression of alanine racemase gene in $X$. oryzae was confirmed by reverse transcriptase (RT)-PCR. Protein concentration was determined according to the method of Bradford [1976] using bovine serum albumin as a standard protein. SDS-PAGE was carried out as described by Laemmli [1970] using 5\% stacking gel and 12.5\% resolving gel, followed by staining of the proteins with Coomassie Brilliant Blue R-250. Unless otherwise mentioned, all of the data were represented as mean values of three independent experiments.

\section{Results and Discussion}

Expression of alanine racemase in E.coli and affinity purification. To obtain a sufficient quantity of the alanine racemase, an attempt was tried to express the enzyme in $E$. coli BL21(DE3)pLys harboring the pET-ala. A routine culture of the cell at $37^{\circ} \mathrm{C}$ and $200 \mathrm{rpm}$ resulted in a formation of inclusion body, thus it was difficult to obtain a soluble form of alanine racemase which shows a considerable activity. Crude extracts were prepared by mechanical disruption, sonication, cell lysis using commercial kit, or combination of each method. In any case, formation of inclusion body was evident under the basis of very low enzyme activity and the absence of the expected protein band on SDS-PAGE of the crude extract prepared (detailed data not shown). In order to avoid a formation of inclusion body which frequently occurs through over-expression mediated by $\mathrm{T} 7$ promoter in E. coli, the cells were cultured under slow growth condition by adjusting the incubation temperature at $25^{\circ} \mathrm{C}$ and keeping an agitation rate below $50 \mathrm{rpm}$. Under this condition, the alanine racemase gene was overexpressed with a soluble form. The cells were collected every 2 $\mathrm{h}$ until $12 \mathrm{~h}$ and the enzyme activity measured. When the bacterial sample was collected after $8 \mathrm{~h}$, the specific activity was the highest, 5.4 U/mg protein (detailed data not shown). Therefore the content of an alanine racemase accumulated in the cell may be relatively the most under this condition of expression, thereby rendering the protein purification more 


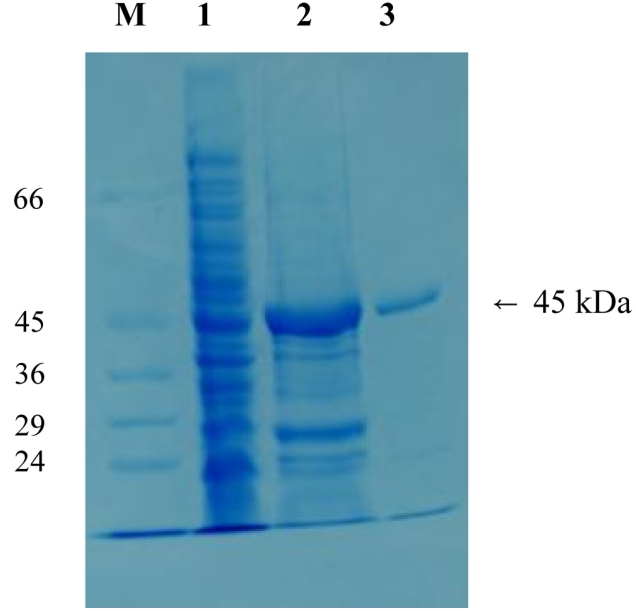

Fig. 1. SDS-PAGE analysis of a purified alanine racemase which was cloned from $X$. oryzae and expressed in $E$. coli. Lane M, molecular mass markers; lane 1, crude extract from $E$. coli BL21(DE3)pLys without insert gene (i.e., vector control); lane 2, crude extract from $E$. coli cell transformed with pET-21-alr; lane 3, an alanine racemase purified by affinity chromatography using nickel charged His-bind resin.
A

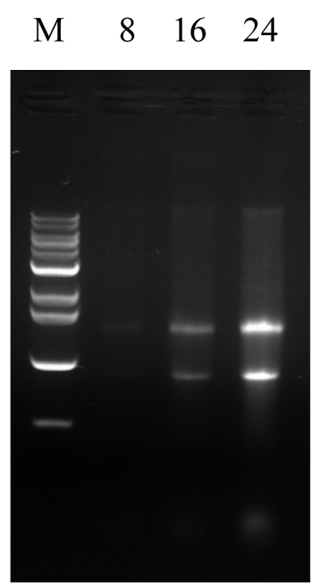

B
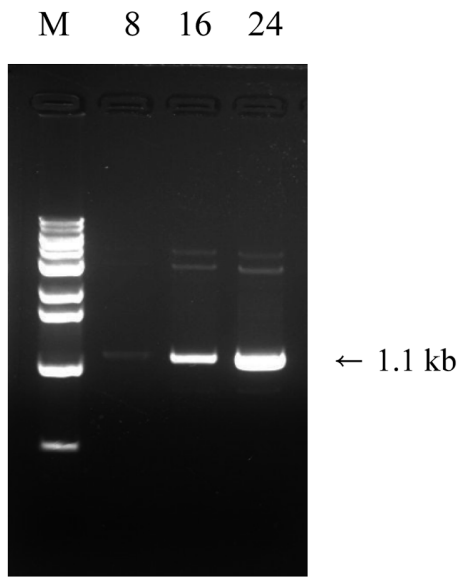

Fig. 2. Extraction of total RNA from $X$. oryzae (A) and reverse transcriptase PCR using the total RNA (B). Total RNAs were extracted at an interval of $8 \mathrm{~h}$ during the culture of bacteria. An expression of alanine racemase gene in $X$. oryzae was confirmed using a reverse transcriptase PCR. The PCR was performed by a reverse transcriptase using the total RNA as a template. M, marker; 8,16 and 24, each time (h) of total RNA extraction.

facile. Purification of the alanine racemase was performed by affinity chromatography owing to six histidine residues of the enzyme. A SDS-PAGE analysis was performed with the active fraction obtained from the affinity chromatography, resulting in one major band with a molecular mass of about $45 \mathrm{kDa}$ (Fig. 1). Affinity purification using His-tag endows other additive advantage that intrinsic alanine racemase in E.coli could be passed without binding to the affinity column.

The molecular weight shows a similar range to the enzyme from other sources such as $41 \mathrm{kDa}$ from Penaeus monodon [Uo
Table 1. Substrate specificity of the purified alanine racemase, which was cloned from X.oryzae and expressed in $E$. coli. The enzyme activities which converts L-amino acid to D-amino acid and vice versa, were measured

\begin{tabular}{lcc}
\hline \hline \multirow{2}{*}{ Substrate } & \multicolumn{2}{c}{ Enzyme activity (U/mg protein) } \\
\hline Alanine & L-Amino acid $\rightarrow$ & D-Amino acid $\rightarrow$ \\
D-Amino acid reaction & L-Amino acid reaction \\
Serine & 11.5 & 9.5 \\
Lysine & 3.7 & 2.1 \\
Arginine & $<0.1$ & $<0.1$ \\
Leucine & $<0.1$ & $<0.1$ \\
Asparagine & $<0.1$ & 0.4 \\
Methionine & $<0.1$ & $<0.1$ \\
Glutamine & $<0.1$ & $<0.1$ \\
Cysteine & 0.9 & $<0.1$ \\
Valine & $<0.1$ & $<0.1$ \\
Glutamic acid & $<0.1$ & $<0.1$ \\
Proline & $<0.1$ & 0.3 \\
Tyrosine & 0.7 & 0.5 \\
Tryptophan & 1.5 & 1.2 \\
Phenylalanine & 1.4 & $<0.1$ \\
Histidine & $<0.1$ & 0.7 \\
Glycine & 1.9 & 1.2 \\
\hline
\end{tabular}

et al., 2001a; 2001b], $45 \mathrm{kDa}$ from Acetobacter aceti [Francois and Kappock, 2007], and $50 \mathrm{kDa}$ from Bifidobacterium bifidum [Yamashita et al., 2003]. However, the molecular weights from Corynebacterium glutamicum or Chlamydomonas reinhardtii [Oikawa et al., 2006; Nishimura et al., 2007] were 78 and 72 $\mathrm{kDa}$, respectively, showing a much difference from our result.

Constituve expression of the alanine racemase gene in $X$. oryzae. If the cloned gene is not constitutively expressed in $X$. oryzae cell, the researches such as biochemical characteristics and inhibition test of alanine racemase would be less valuable. In this regard, an expression of the cloned gene in $X$. oryzae was tested by a reverse transcriptase PCR technique (Fig. 2). Total RNAs were extracted from the cells ranging from logarithmic to stationary phase and analyzed for the gene expression. The primers used for this PCR technique were the same as those for the cloning of alanine racemase gene. The result of PCR product represents a gradual increase of $1.1 \mathrm{~kb}$ along with the incubation time, which corresponds to the cloned gene. Therefore, this result indicates that the cloned gene might be constitutively expressed in $X$. oryzae cell.

Substrate specificity of purified alanine racemase. The purified alanine racemase was assayed using different L or Damino acids as substrate and interconversions between L- and Damino acids were measured (Table 2). The highest activity as measured by the production of D-amino acid was observed with the enzymatic incubation using L-alanine as a substrate, showing the activity of $11.5 \mathrm{U} / \mathrm{mg}$ protein. The highest reaction of $\mathrm{D}-$ to L-amino acid production was also occurred by the enzymatic 
Table 2. Eventual inhibition of the alanine racemase activity, which was cloned from $X$. oryzae and expressed in $E$. coli. The enzyme activities which converts $L$-amino acid to D-amino acid or vice versa, were measured. Concentration of each inhibitor was $10 \mathrm{mM}$ of amino acid

\begin{tabular}{cccc}
\hline \hline & \multicolumn{2}{c}{ Enzyme activity (U/mg protein) } \\
\hline Inhibitor & $\begin{array}{c}\text { L-Amino acid } \rightarrow \\
\text { D-Amino acid reaction }\end{array}$ & Inhibitor & $\begin{array}{c}\text { L-Amino acid } \rightarrow \\
\text { D-Amino acid reaction }\end{array}$ \\
\hline Control & 12.4 & Control & 9.8 \\
L-Ala & 14.5 & D-Ala & 10.1 \\
L-Ser & 10.2 & D-Ser & 7.8 \\
L-Lys & 7.5 & D-Lys & 6.4 \\
L-Arg & 10.4 & D-Arg & 10.2 \\
L-Leu & 12.1 & D-Leu & 11.4 \\
L-Asn & 13.1 & D-Asn & 10.5 \\
L-Met & 10.7 & D-Met & 8.5 \\
L-Gln & 9.5 & D-Gln & 7.9 \\
L-Cys & 2.5 & D-Cys & 2.4 \\
L-Val & 13.1 & D-Val & 12.3 \\
L-Glu & 11.4 & D-Glu & 7.9 \\
L-Pro & 10.8 & D-Pro & 7.8 \\
L-Tyr & 10.6 & D-Tyr & 10.2 \\
L-Trp & 9.4 & D-Trp & 10.7 \\
L-Phe & 8.4 & D-Phe & 8.8 \\
L-His & 10.5 & D-His & 10.2 \\
Gly & 11.3 & Gly & 9.8 \\
\hline
\end{tabular}

reaction with D-alanine as a substrate, but to a lesser extent than the conversion rate of $\mathrm{L}-$ to D-alanine reaction. Productions of Lor D-serine were also observed but the activities were less compared with the production of L- or D-alanine. With other amino acids, essentially no detectable activities of racemase were found in any directions of L- or D-amino acid production.

Taken together, the gene annotated as a putative alanine racemase in NCBI data bank is considered as a gene coding for an evident alanine racemase under the basis of data that represents a substrate specificity as well as a racemic reaction. Similar to our result, alanine racemases from Penaeus monodon [Uo et al., 2001a; 2001b] or B. bifidum [Yamashita et al., 2003] showed some activity with L-serine as well as L-alanine. However, the enzyme from Corynebacterium glutamicum did not show any enzyme activity with L-serine [Oikawa et al., 2006]. Thus, it would be necessary to further research whether alanine racemase is involved in the biosynthesis of D-serine in bacterial cells.

Effect of PLP on the enzyme activity The enzyme activity of alanine racemase was measured in the presence of PLP (Fig. 3 ). In the absence of PLP, the enzyme activity was $11.2 \mathrm{U} / \mathrm{mg}$ protein. Addition of PLP up to about $0.3 \mathrm{mM}$ gradually enhanced the enzyme activity, showing $172 \%$ activity of control at 0.3 $\mathrm{mM}$.

Up to now, it has been shown that many of alanine racemase need PLP as a cofactor [Francois and Kappock, 2007]. However, an alanine racemase from Bacillus anthracis [Kanodia et al.,

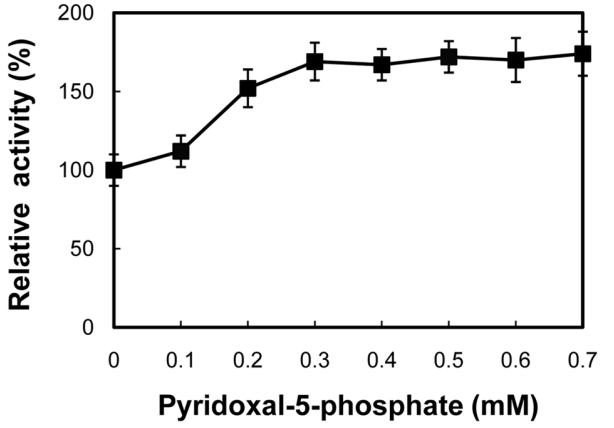

Fig. 3. Effect of PLP on the alanine racemase activity from X.oryzae. The purified alanine racemase was assayed in the presence or absence of PLP. The activity without PLP was considered as $100 \%$ activity which was equivalent to $11.2 \mathrm{unit} / \mathrm{mg}$ protein.

2008] showed considerable activity without PLP and the activity increased by addition of PLP [Kanodia et al., 2008]. The alanine racemase, in this experiment, is similar to the alanine racemase from B.anthracis in the light of PLP dependency. On the analogy of our result and the previous findings, PLP, a cofactor might be weakly bound to the alanine racemase by non-covalent binding. Thus it is speculated that PLP bound to the enzyme might be gradually lost during protein purification procedure. Therefore supplement of PLP would be necessary for the full activation of the enzyme.

Eventual inhibition of alanine racemase activity by amino acids. An inhibitory effect of amino acids on the alanine racemase was performed by measuring the enzymatic activity converting L-alanine to D-alanine or vice verse in the presence of different amino acids (10 $\mathrm{mM})$ as inhibitor (Table 2). Among the amino acids tested, L- or D-cysteine considerably inhibited the alanine racemase activity to the extent of 79 and $76 \%$ inhibition, respectively. Secondly, L- or D-lysine also inhibited the enzyme activities, showing 40 and $35 \%$ inhibition, respectively. Other amino acids appears to less inhibit the enzyme or do not affect the enzyme activity at all. Therefore the inhibitory effect by L- or D-cysteine was further examined in detail by measuring the activity in the presence or absence of PLP, a general cofactor of alanine racemase (Fig. 3). In the presence of PLP, the enzyme activity was inhibited by L- or D-cysteine, showing 65 and $67 \%$ activities of control at $2 \mathrm{mM}$ addition (i.e, 35 and $37 \%$ inhibition), respectively. In the absence of PLP, the activities also much decreased and the extent of decrease appears to be more significant than that in the presence of PLP.

Similar to our result, it has been reported that enzyme activities of alanine racemase from Bacillus cereus [Preston and Douthit, 1984], Lactobacillus fermenti [Johnston, 1969], or Tolypocladium niveum [Hoffmann et al., 1994] were inhibited by D-cysteine. But the enzyme from E.coli was not inhibited by D-cysteine [Lambert and Neuhaus, 1972]. In general, cysteine is neither a substrate of the alanine racemase nor an analogue of 

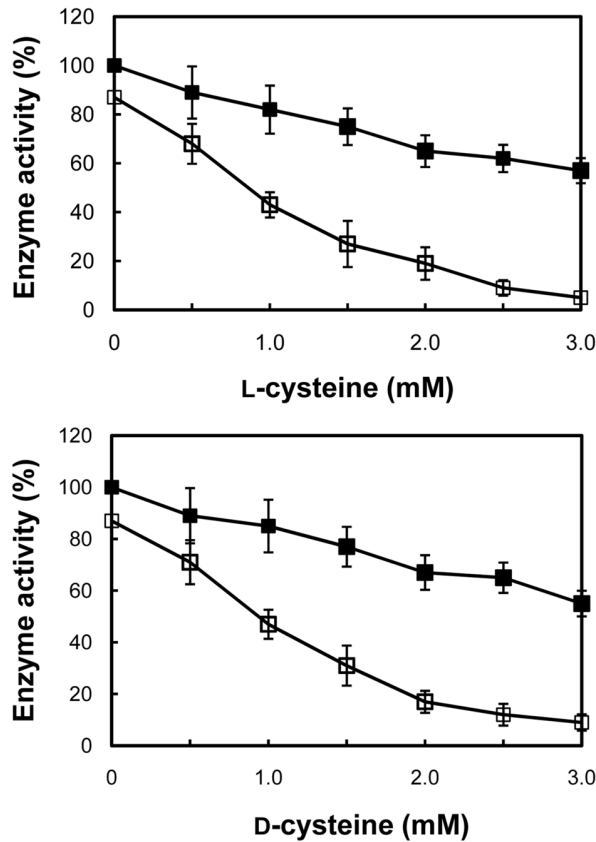

Fig. 4. Influence of $L$ - or D-cysteine on the activity of the alanine racemase. Inhibitory effects of L- or D-cysteine on the alanine racemase activity were assayed in the presence $(1 \mathrm{mM},-\square-)$ or absence (- $\square$-) of PLP. One hundred percent activity was equivalent to $10.6 \mathrm{U} / \mathrm{mg}$ protein.

the substrate. But the enzyme activity is often inhibited by D- or L-cysteine, more or less. It has been well known that cysteine binds to PLP not only in vivo [Buell and Hansen, 1960] but also in vitro [Mackay, 1962] without aid of enzymatic reaction. Under the basis of these findings, D- or L-cysteine might bind to PLP of the alanine racemase, thereby appears to inhibit the enzymatic activity. Similar to our result, D- or L-cysteine inhibited the activity of serine racemase from mouse, which is also one of PLP-dependent enzyme [Panizzutti et al., 2001]. Cysteine is considered as an analogue of serine in that these amino acids carry an alcohol group. Thus this group could be involved in the binding of alanine racemase.

Optimum pH and pH stability Optimum $\mathrm{pH}$ of the alanine racemase was assayed by measuring the enzyme activities which converts L-alanine to D-alanine or vice versa (Fig. 5). In the reaction of $\mathrm{L}$-alanine to $\mathrm{D}$-alanine production, optimum $\mathrm{pH}$ was observed around $\mathrm{pH}$ 8.0. The opposite reaction, D-alanine to Lalanine, was also the most reactive at $\mathrm{pH}$ 8.0. In both reactions, the enzyme aivivities gradually decreased at $\mathrm{pH}$ above 9.0 or acidic $\mathrm{pH}$. The optimum $\mathrm{pH}$ is similar to those of $E$. coli, $B$. bifidum, A. aceti, and Bacillus pseudofirmus OF4 [Lambert and Neuhaus, 1972; Yamashita et al., 2003; Ju et al., 2005; Francois and Kappock, 2007]. pH stability of the alanine racemase was measured at the $\mathrm{pH}$ values ranging from $\mathrm{pH} 4.0$ to 11.0. After storage for $4 \mathrm{~h}$ at different $\mathrm{pH}$ values, $\mathrm{pH}$ stability was assessed by measuring the residual activities (Fig. 6). When the enzyme
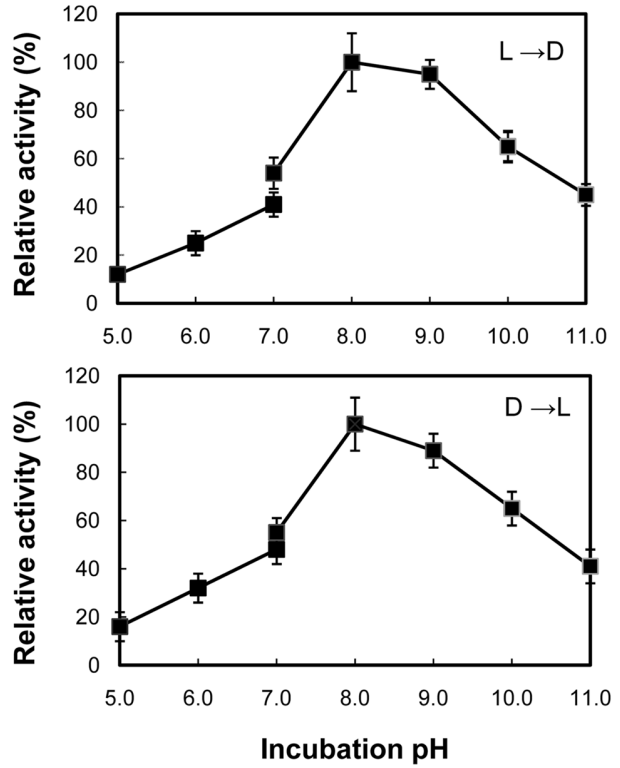

Fig. 5. pH effect on the alanine racemase activity of X.oryzae. The reaction mixture consisted of potassium phosphate for $\mathrm{pH}$ 5.0-7.0 and Tris-Cl for $\mathrm{pH}$ 7.0-11.0. Maximum activities were considered as $100 \%$, equivalent to 12.0 and $10.9 \mathrm{U} / \mathrm{mg}$ protein (for $\mathrm{L} \rightarrow \mathrm{D}$ and $\mathrm{D} \times \mathrm{L}$ reaction, respectively).

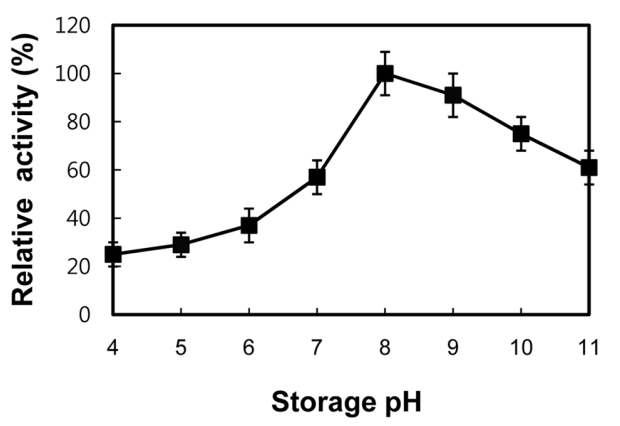

Fig. 6. pH stability of the alanine racemase activity from $X$. oryzae. The alanine racemase was suspended in different buffers showing $\mathrm{pH}$ ranges from 4.0 to $11.0 ; 50 \mathrm{mM}$ citrate phosphate buffer for $\mathrm{pH} 4.0$ 5.0 , potassium phosphate buffer for $\mathrm{pH}$ 6.0-7.0, and Tris- $\mathrm{Cl}$ buffer for $\mathrm{pH} 8.0-11.0$. After $4 \mathrm{~h}$ incubation, an aliquot was withdrawn and the alanine racemase activity was measured under standard assay condition. Maximum activity at $\mathrm{pH} 8.0$ was considered as $100 \%$ activity equivalent to $12.3 \mathrm{U} / \mathrm{mg}$ protein. Each point represents the average of three experiments.

was treated at $\mathrm{pH} 8.0$, the stability appears to be the most satisfactory. The stability of enzyme drastically decreased especially under acidic $\mathrm{pH}$ condition, showing only $27 \%$ of maximum activity by treatment of $\mathrm{pH}$ 5.0. Overally the enzyme appears to be more stable at weak alkaline $\mathrm{pH}$ than acidic $\mathrm{pH}$.

Acknowledgments. This study was carried out with the support of "Research program for Agricultural Science and Technology Development (Project No. PJ006643)", National Academy of Agricultural Science, Rural Development Administration, Republic of Korea. 


\section{References}

Badet B and Walsh C (1985) Purification of an alanine racemase from Streptococcus faecalis and analysis of its inactivation by (1aminoethyl) phosphonic acid enantiomers. Biochemistry 24, 1333-1341.

Bradford MM (1976) A rapid sensitive method for the quantitation of microgram quantities of protein utilizing the principle of protein dye binding. Anal Biochem 72, 248-254.

Buell MV and Hansen RE (1960) Reaction of pyridoxal 5 phosphate with aminothiols. J Am Chem Soc 82, 6042-6049.

Copie V, Faraci WS, and Walsh CT (1988) Inhibition of alanine racemase by alanine phosphonate: detection of an imine linkage to pyridoxal 5'phosphate in the enzyme-inhibitor complex by solidstate N15-nuclear magnetic resonance. Biochemistry 27, 49664970.

Erion MD and Walsh CT (1987) 1-Aminocyclopropane-phosphonate: Time-dependen inactivation of 1-aminocyclopropanecarboxylate deaminase and Bacillus stearothermophilus alanine racemase by slow dissociation behavior. Biochemistry 26, 3417-3425.

Faraci WS and Walsh CT (1989) Mechanism of inactivation of alanine racemase by $\beta, \beta, \beta$-trifluoroalanine. Biochemistry 28, 431-437.

Francois JA and Kappock TJ (2007) Alanine racemase from the acidophile Acetobacter aceti. Prot Exp Purif 51, 39-48.

Hoffmann K, Schneider-Scherzer E, Kleinkauf H, and Zocher R (1994) Purification and characterization of eukaryotic alanine racemase acting as key enzyme in cyclosporine biosynthesis. $J$ Biol Chem 269, 12710-12714.

Johnston M (1969) Studies on amino acid racemases. J Biol Chem 244, 5414-5420.

Ju J, Yokoigawa K, Misono H, and Ohnishi K (2005) Cloning of alanine racemase genes from Pseudomonas fluorescens strains and oligomerization states of gene products expressed in Escherichia coli. J Biosci Bioeng 100, 409-417.

Kanodia S, Agarwall S, Singh P, Singh P, and Bhatnagar R (2008) Biochemical characterization of alanine racemase; a spore protein produced by Bacillus anthracis. Biochem Mol Biol Rep 42, 47-52.

Kuniki K, Masaru S, and Yoneyama M (2007) Synthesis of DLtryptophan by modified broad specificity amino acid racemase from Pseudomonas putida IFO 12996. Appl Microbiol Biotechnol 73, 1299-1305.

Laemmli UK (1970) Cleavage of structural proteins during the assembly of the head of bacteriophage T4. Nature 227, 680-685.

Lambert MP and Neuhaus FC (1972) Mechanism of D-cycloserine action: Alanine racemase from Escherichia coli W. J Bacteriol 110, 978-987.

Liardon R and Hurrell RF (1983) Amino acid racemization in heated and alkali-treated proteins. J Agric Food Chem 31, 432-437.

Lobocka M, Hennig J, and Wild J (1994) Organization and expression of the Escherichia coli $\mathrm{K}-12$ dad operon encoding the smaller subunit of D-amino acid dehydrogenase and the catabolic alanine racemase. J Bacteriol 176, 1500-1510.

Mackay D (1962) The mechanism of the reaction of cysteine with pyridoxal 5-phosphate. Arch Biochem Biophys 99, 93-100.

Nishimura K, Tomoda Y, Nakamoto Y, Ishii Y, and Nagata Y (2007) Alanine racemase from the green alga Chlamydomonas reinhardtii. Amino acids 32, 59-62.

Noda M, Matoba Y, Kumagai T, and Sugiyama M (2004) Structural evidence that alanine racemase from a D-cycloserine-producing microorganism exhibits resistance to its own product. $J$ Biol Chem 279, 46153-46161.

Nomura T, Yamamoto I, Morishita F, Furukawa Y, and Matsushima O (2001) Purification and some properties of alanine racemase from a bivalve mollusk Corbicula japonica. J Exp Zool 289, 1-9.

Oikawa T, Tauch A, Schaffer S, and Fujioka T (2006) Expression of alr gene from Corynebacterium glutamicum ATCC 13032 in Escherichia coli and molecular characterization of the recombinant alanine racemase. J Biotechnol 125, 503-512.

Panizzutti R, Miranda JD, Ribeiro CS, Engelender S, and Wolosker H (2001) A new strategy to decrease $N$-methyl-D-aspartate (NMDA) receptor coactivation: Inhibition of D-serine synthesis by converting serine racemase into an eliminase. Proc Natl Acad Sci USA 98, 5294-5299.

Preston RA and Douthit HA (1984) Germination of Bacillus cereus spores: Critical control by DL-alanine racemase. J Gen Microbiol 130, 3123-3133.

Saito M, Nishimura K, Hasegawa Y, Shinohara T, Wakabayashi S, Kurihara T, Ishizuka M, and Nagata Y (2007) Alanine racemase from Helicobacter pylori NCTC11637. Life Sci 80, 788-794.

Sambrook J and Russel DW (2001) In Molecular Cloning: A Laboratory Manual, (3rd ed.), Cold Spring Harbor Laboratory Press, Cold Spring Harbor, NY.

Shibata K, Shirasuna K, and Motegi K (2000) Purification and properties of alanine racemase crayfish Procambarus clarkia. Comp Biochem Physiol 126, 599-608.

Silverman RB (1988) The potential use of mechanism based enzyme inactivators. J Enz Inhib 2, 73-90.

Strych U, Huang HC, Krause KL, and Benedik MJ (2000) Characterization of the alanine racemase from Pseudomonas aeruginosa PAO1. Curr Microbiol 41, 290-294.

Uo T, Ueda M, Nishiyama T, Yoshimura T, and Esaki N (2001b) Purification and characterization of alanine racemase from hepatopancreas of black-tiger prawn, Penaeus monodon. $\mathrm{J} \mathrm{Mol}$ Cat 137-144.

Uo T, Yoshimura T, Tanaka N, Takegawa K, and Esaki N (2001a) Functional characterization of alanine racemase from Schizosaccharomyces pombe: A eukaryotic counterpart to bacterial alanine racemase. J Bacteriol 183, 2226-2233.

Wang E and Walsh CT (1978) Suicide substrates for the alanine racemase of Escherichia Coli. Biochemistry 17, 1313-1321.

Yamashita T, Ashiuchi M, Ohnishi K, Kato S, Nagata S, and Misono $\mathrm{H}$ (2003) Molecular characterization of alanine racemase from Bifidobacterium bifidum. J Mol Cat B 23, 213-222.

Zhang X, Jantama K, Moore JC, and Shanmugam KT (2007) Production of L-alanine by metabolically engineered Escherichia coli. Appl Microbiol Biotechnol 77, 355-366. 